\title{
THE EXTENSION ROLE OF LOCAL LEADERS IN THE PRODCUTION OF NON-TRATITIONAL FEED FROM AGRICULTURAL WASTE IN KAFR EL-SHEIKH AND BIALA DISTRICTS, KAFR EL-SHEIKH GOVERNORATE
}

Abou Zaiud, R. H. A.

Agric. Extension\& Rural Develop. Res. Inst. - ARC

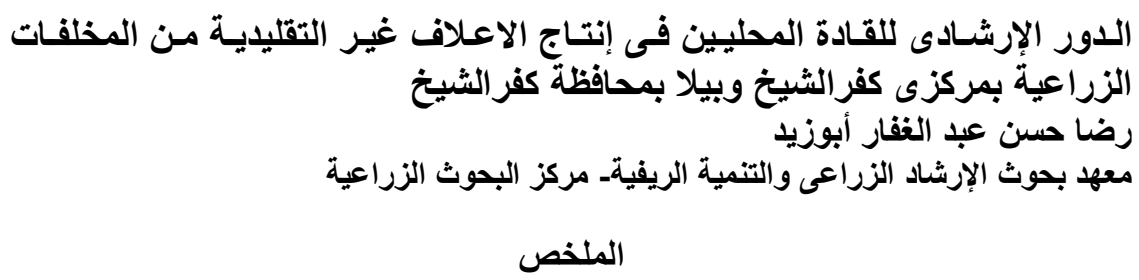

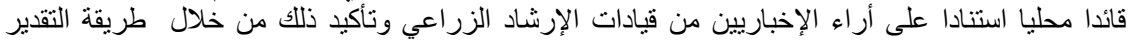

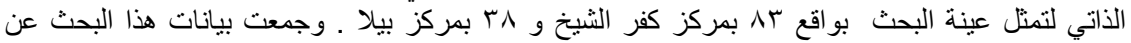

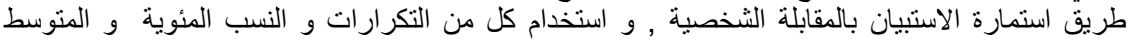

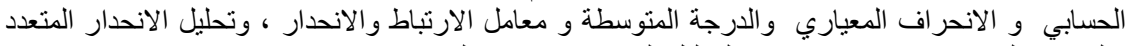

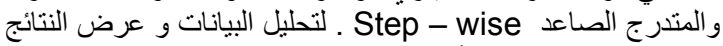
و و الث تمثلت ابرز النتائج في الاتى :

ا ـ أن قرابة به ب م من القادة المحليين المبحوثين من ذوى المستوى المتوسط من حيث القيام بإنتاج الأعلاف

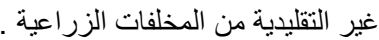

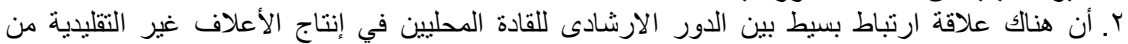

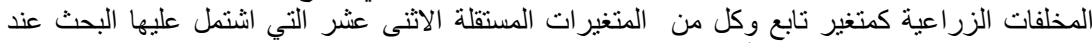

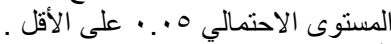

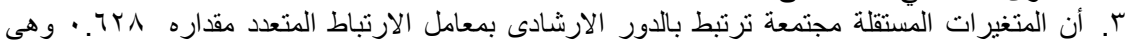

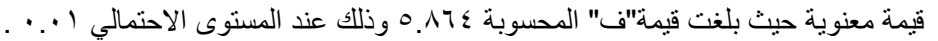

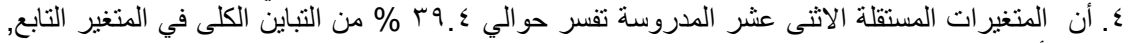

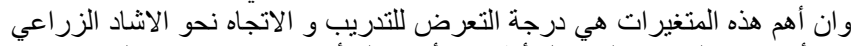

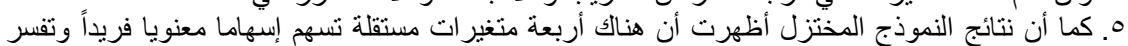

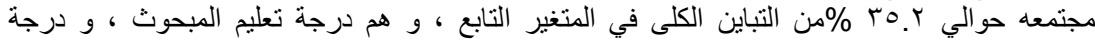

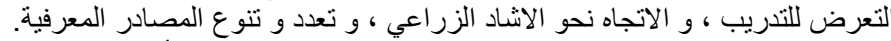
7. أن غالبية القادة المحليين المبحوثين ذوى اتجاه ايجابي نحو إنتاج الأعلاف غير التقليدية من المخلفات

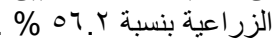

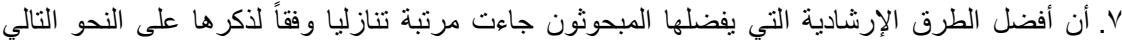

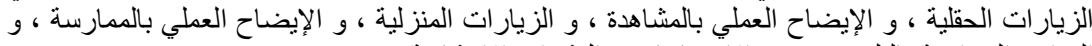

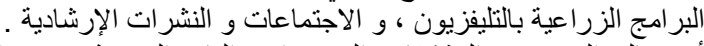

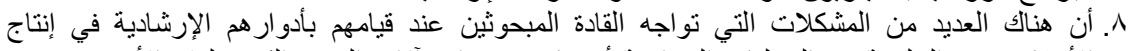

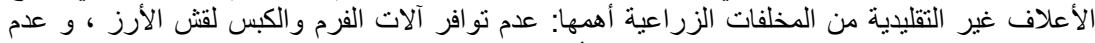

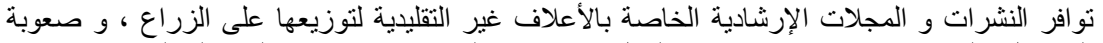

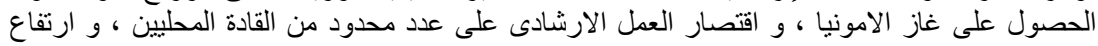


Abou Zaiud, R. H. A.

أسعار حقن قش الأرز بالامونيا ، و عدم تو افر السائل المفيد عند الحاجة إليه ، و قله التنديب الكافي للقادة

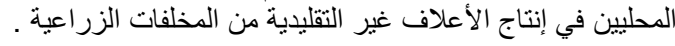

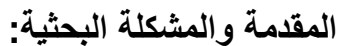

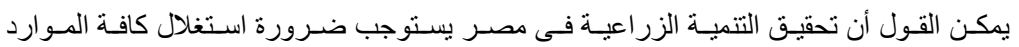

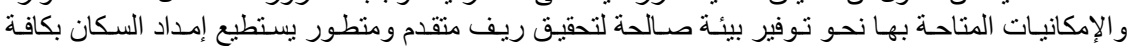

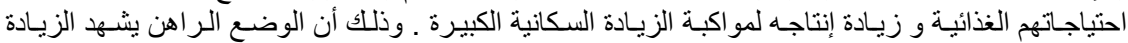

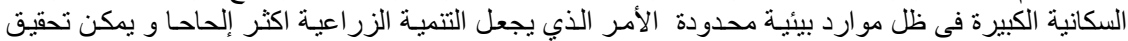
ذللك من خلال التوسع الزر اعي الر أسي والأفقي.

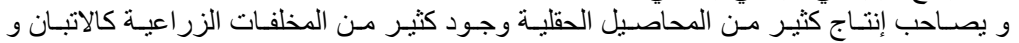

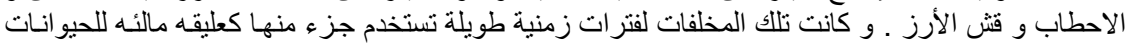

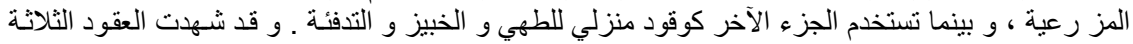

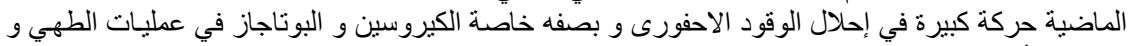

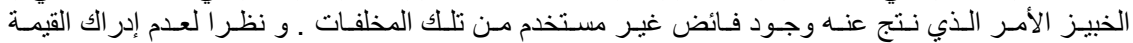

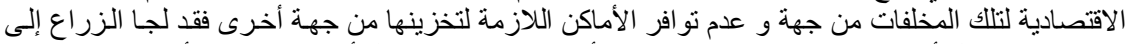

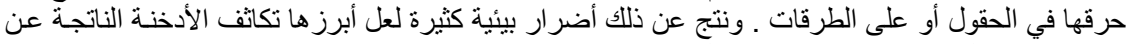

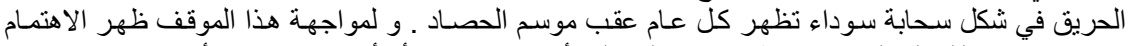
بالاستفادة من تلك المخلفات عن طريق تحويلها إلى أسمدة عضوية أو أو أعلاف حيو انية أو منتجات صناج صناعية

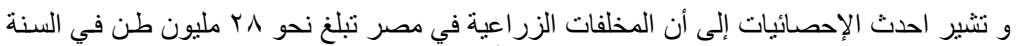
أخرى . الأفئمة

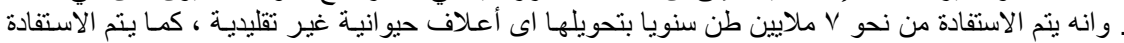

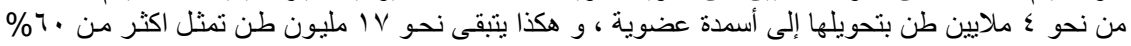
من المخلفات الزراعية غير مستغلة و يهدر معظمها بالحرق . (http://digital.ahram.org.eg/articles.aspx?serial=40774\&eid=907)

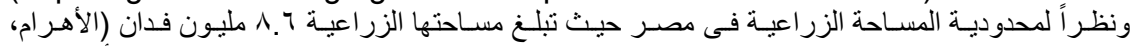

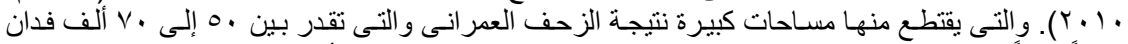

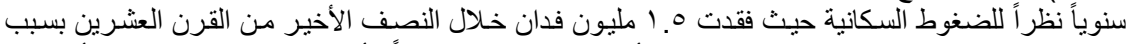

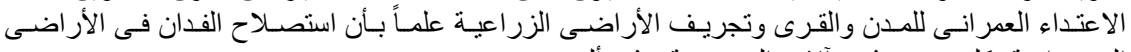
(http://news.Maktoob.com/article/585262/)

الصحراوية يكلف من عشرة آلاف إلى خمسة عشر ألف جنيه.

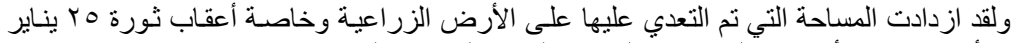

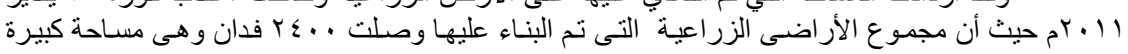

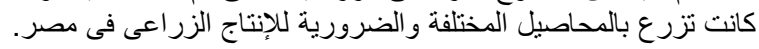

(htpp://www.elbashayer.com/news-128987.html.

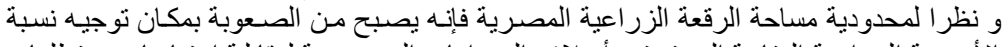

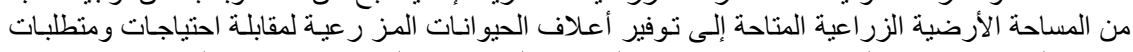

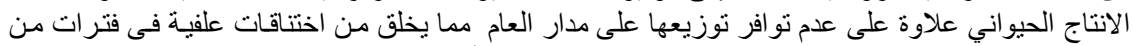

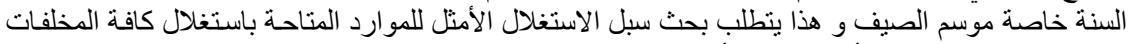

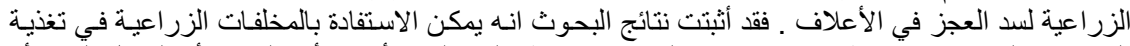

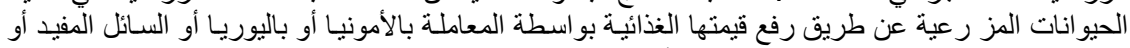

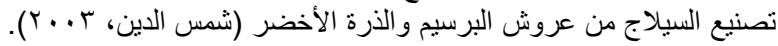

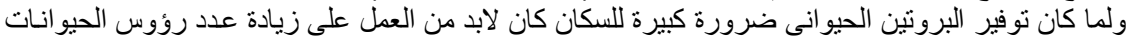

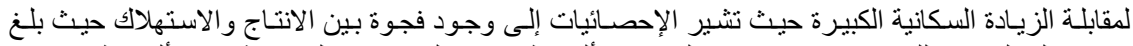

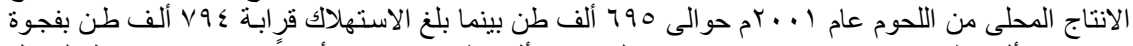

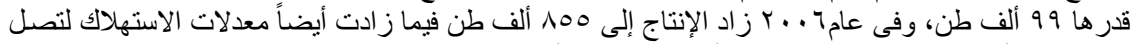

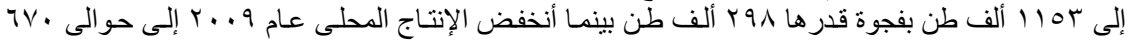




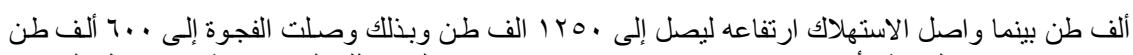

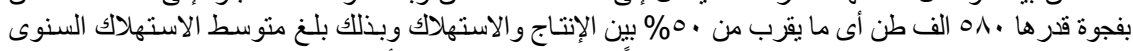

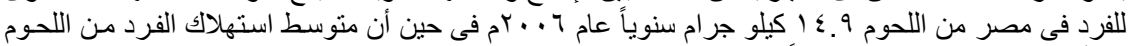

(http://www.Lightsislam.com/t2606-topic)

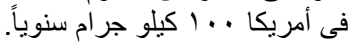

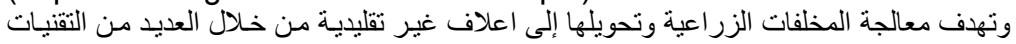

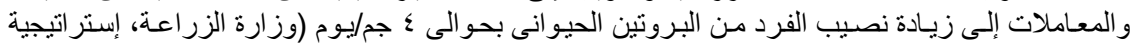

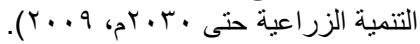

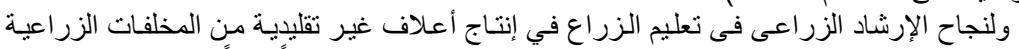

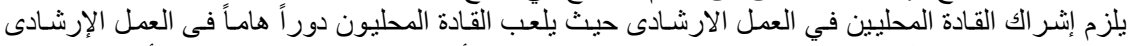

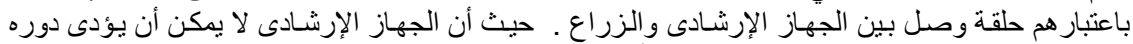

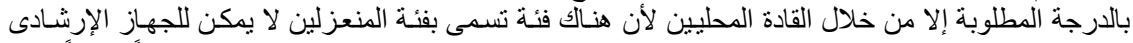

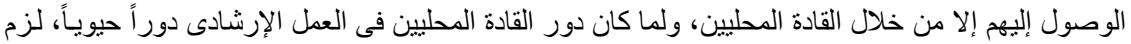

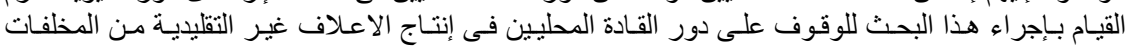

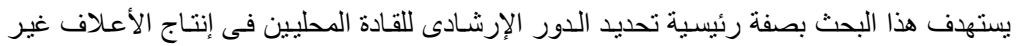

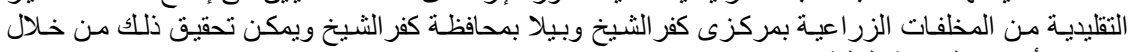
تحقيق الأهداف الفرعية التالية :

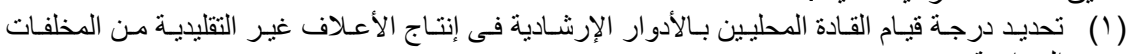
الزئة إعبة

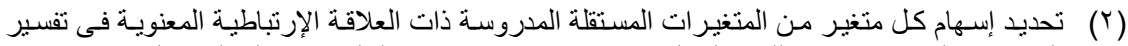

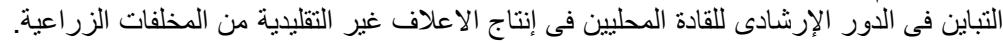

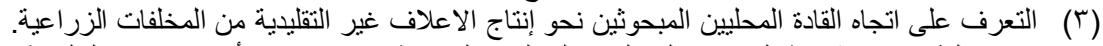

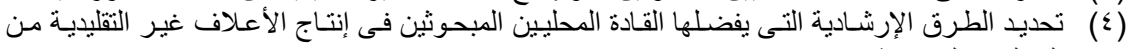
المخلفات الزر اعية.

(0) التعرف على المشكلات التى تواجـا القـادة المحليين المبحوثين عند القيام بـأدوار هم الإرشـادية فى إنتاج الأعلاف غير التقليدية من المخلفات الزفات الزراعية.

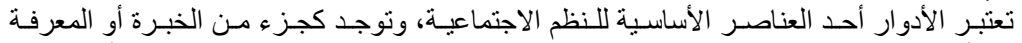

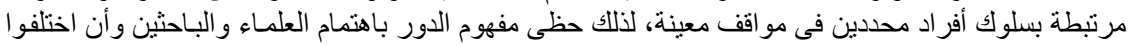

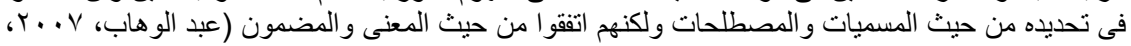

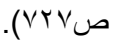

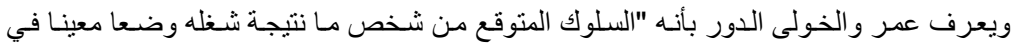

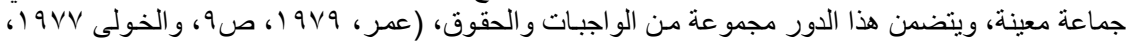

كما يعرف الدور في قاموس العلوم السلوكية بأنه "نمط من السلوك الذى يميز ويتوقع من فرد يشـل

ص (0)

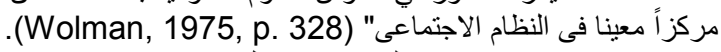

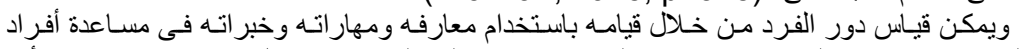

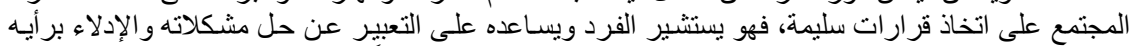

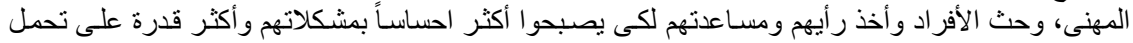

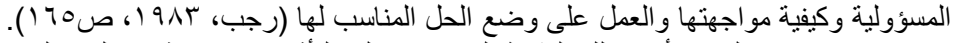

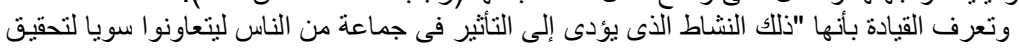

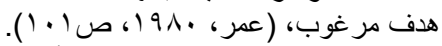

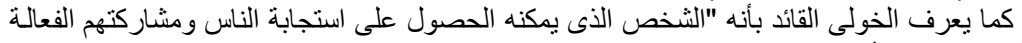

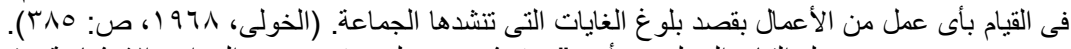

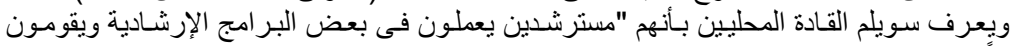

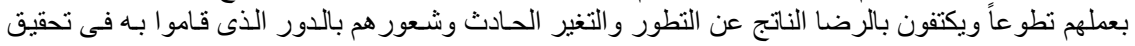


Abou Zaiud, R. H. A.

ذللك التغيير ويقع على عاتقهم جذب أقرانهم للعمل وحفز هم على المشاركة و القيام ببعض الوالو اجبات القيادية

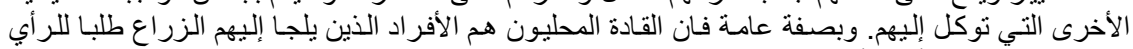
والمشورة في احد الأمور أو المشاكل التي تهمهم تلفي وينقسمون إلى الى الحن

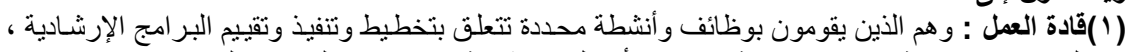

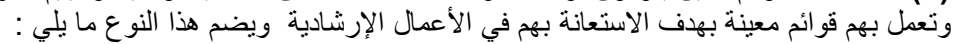

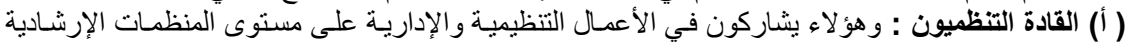
المحلية.

(ب) قادة مهتمون بمجالات معينة : و وهم الأثخاص الذين لهم نثاط في مجال معين ويقومون بتعليمة للآخرين

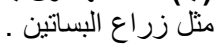
(ج) وهؤلاء يمكن أن يساهموا بنشاط معين مثل إقامة الحقول الإرشادية في مزار عهر.

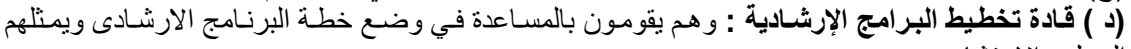

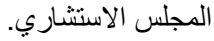

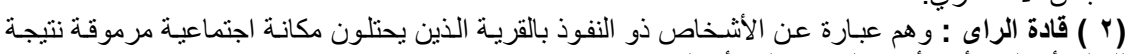

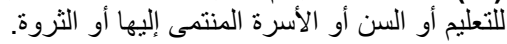

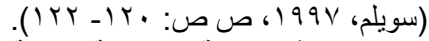
دور القيادة في التنمية الإشنادية الريفية :

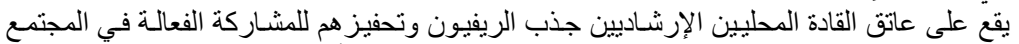

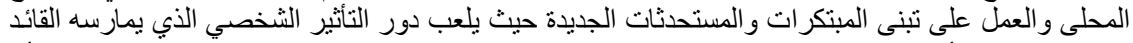

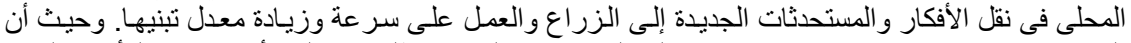

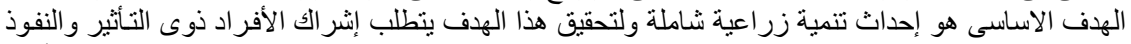

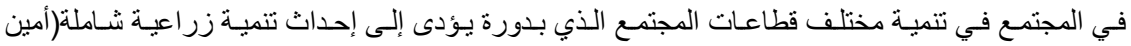
(0: : r...9، الأدوار و المهام التي يقوم بها القادة المحليين في العمل الارشادى:

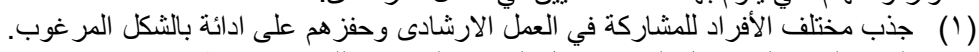

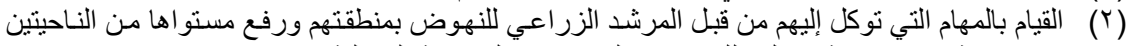

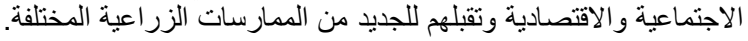

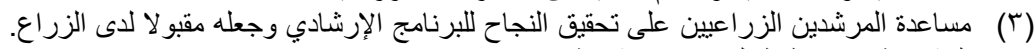
( ) المشاركة في تخطيط البر امج الإرشادية.

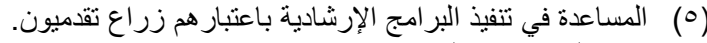
(7) الإنشر الك في تقييم البرامج الإرشادية.

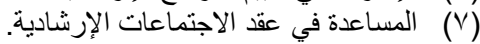

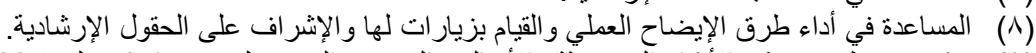

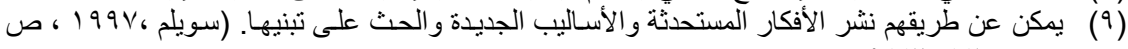

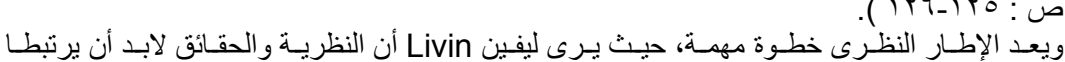

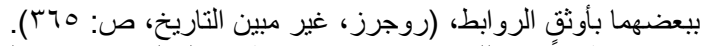

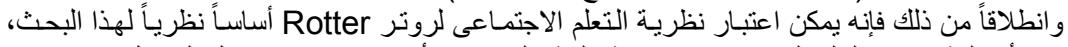

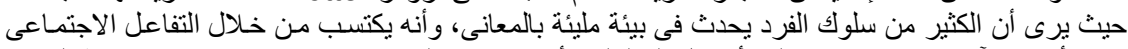

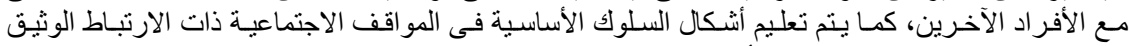

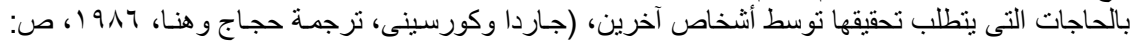

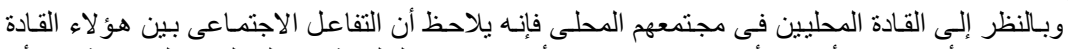

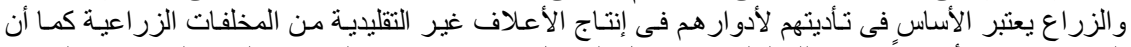

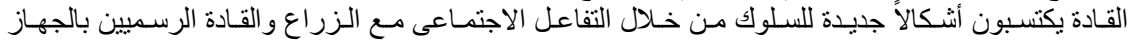

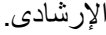

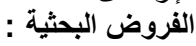
لتحقيق الهدف الثنانى من أهداف البحث تم صياغة الفروض البحثية النالية : 
توجد علاقة إرتباطية معنوية بين الدور الإرشـادى للقادة المحليين فى إنتاج الأعلاف غير التقليديـة من

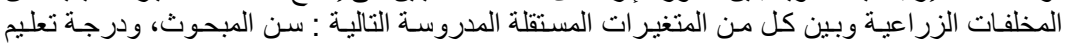

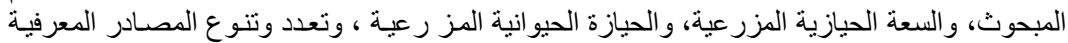

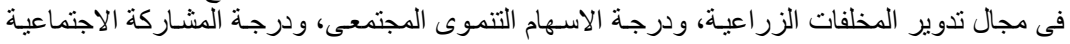

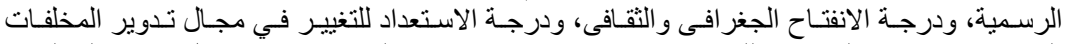

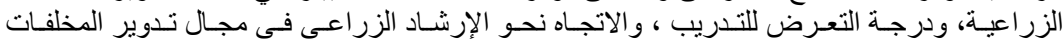

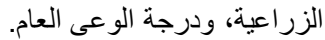
ترتبط المتغيرات المستقلة سابقة الذكر مجتمعة بالدور الإرشادى للقادة المحليين فى إنتاج الاعـلاف غير التقليدية من المخلفات الزر اعية.

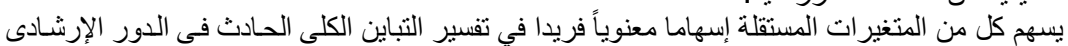

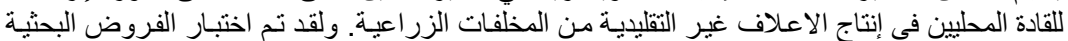
السابقة فى صورنها الصفرية.

\section{الطريقة البحثبة}

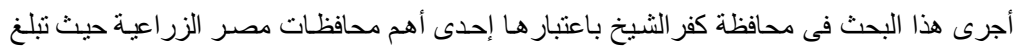

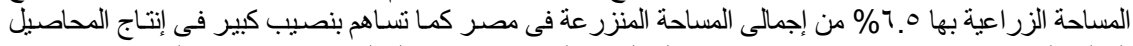

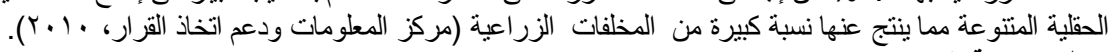

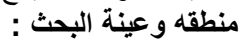

أجريت هذه الدراسة بمركزي كفر الثيخ و بيلا بمحافظة كفر الثيخ و يرجع اختئيار هما لقيام الحملة

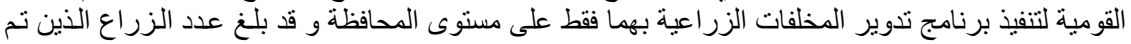

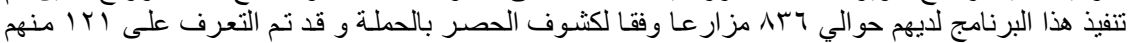

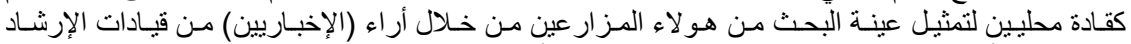

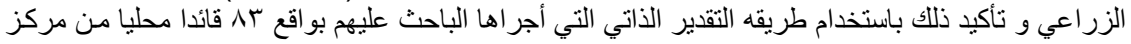

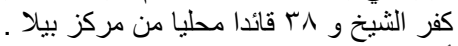

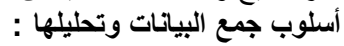

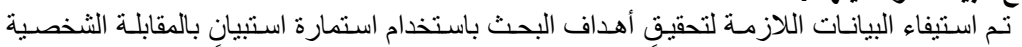

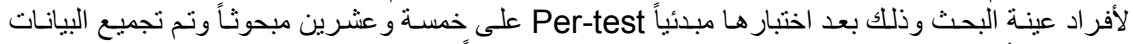

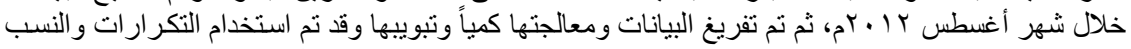

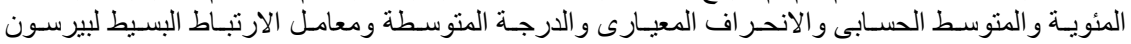

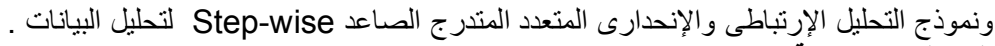

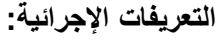

• القادة المحليين : ويقصد بالقادة: المحليين في هذا البحث المسترشدين الذين قاموا بدور ارشـادى في إطسار الحملة

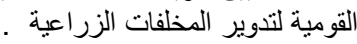

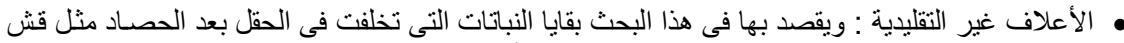

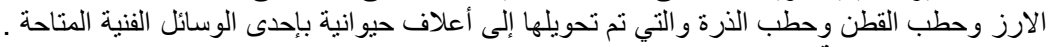

قياس المتغيرات المستقلة:

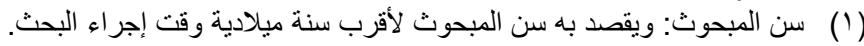

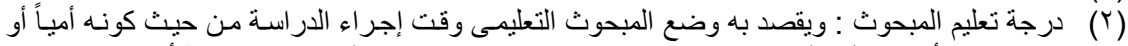

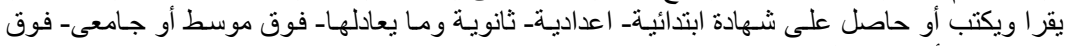

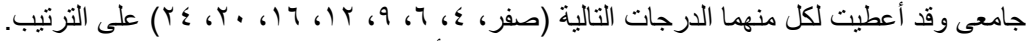

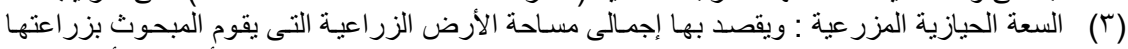

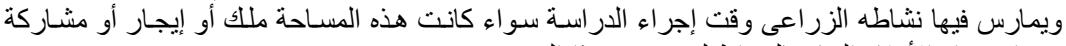

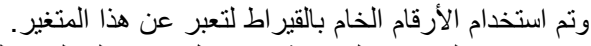

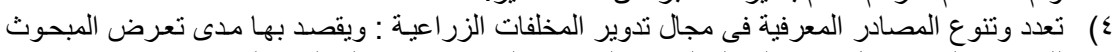

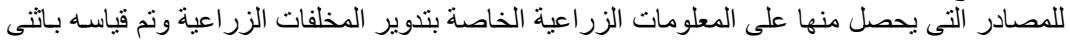


Abou Zaiud, R. H. A.

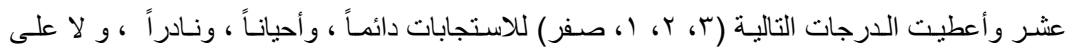

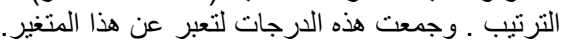

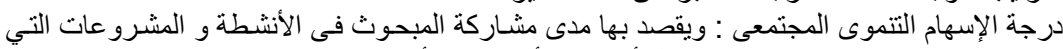

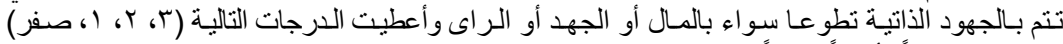

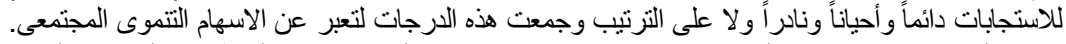

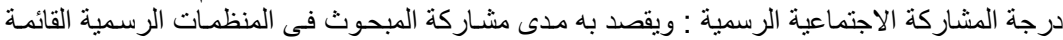

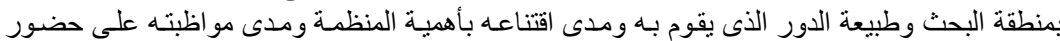

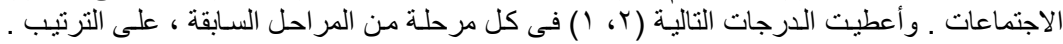

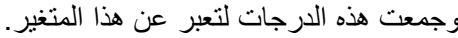

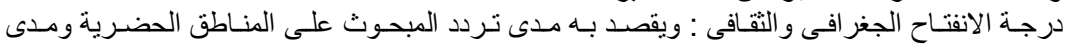

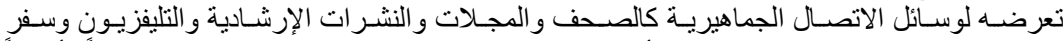

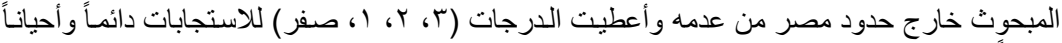

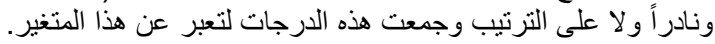

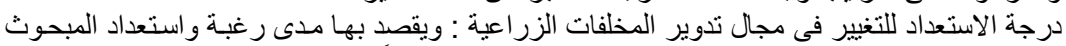

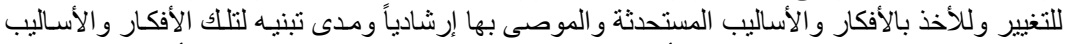

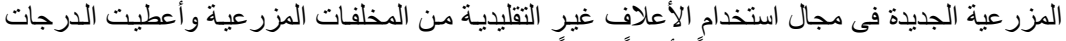

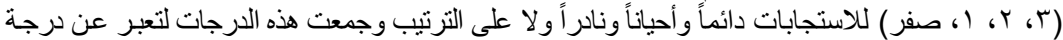
الاستعداد للتغيير.

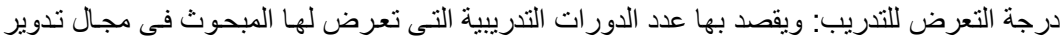

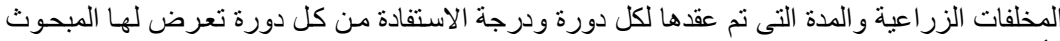

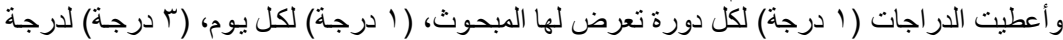

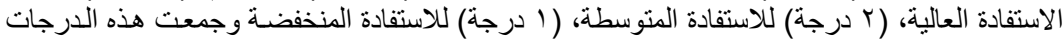

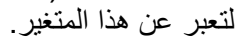

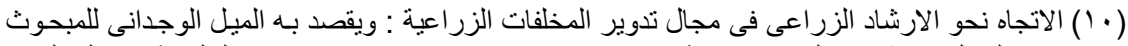

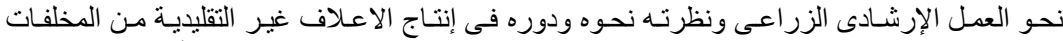

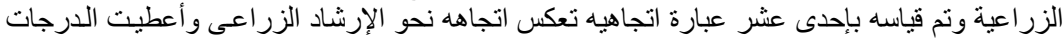

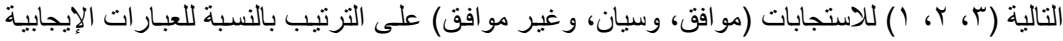

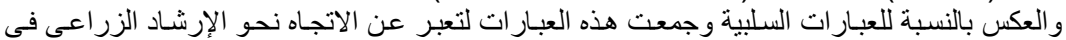
مجال تدوير المخلفات الزبنة الزبار العية.

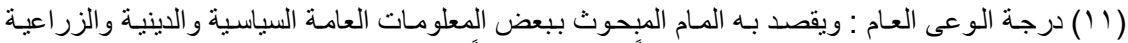

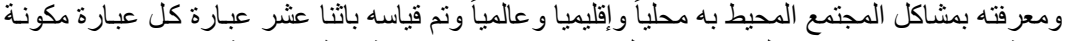

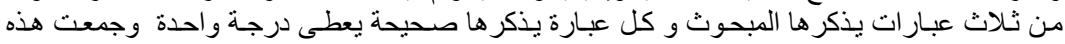

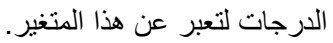

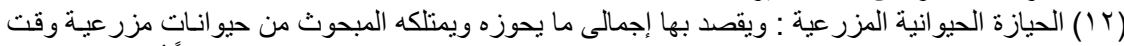

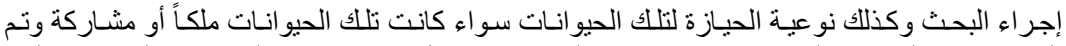

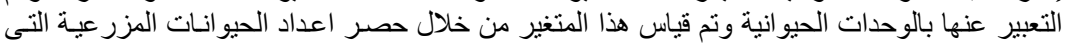

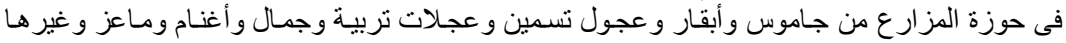

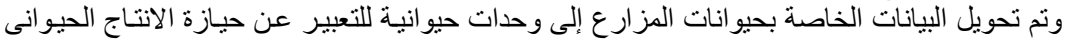

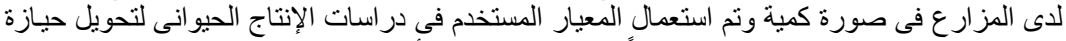

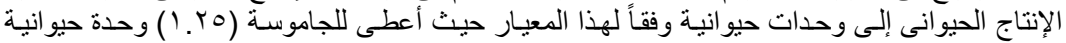

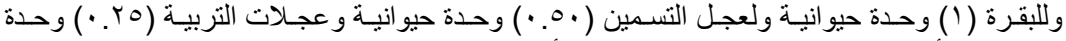

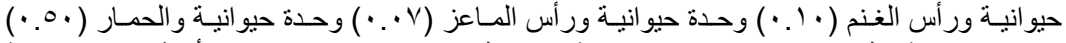

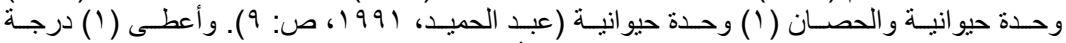

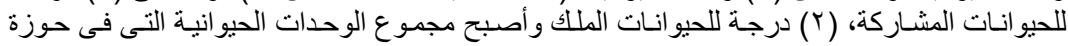

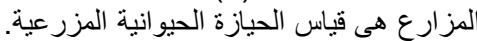
قياس المتغير التابع : ا- الدور الإرشادى للقادة المحليين فى إنتاج الأعلاف غير التقليلية من المخلفات الزراعية: 


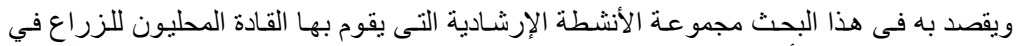

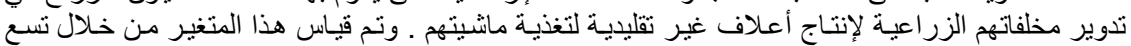

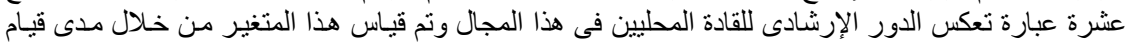

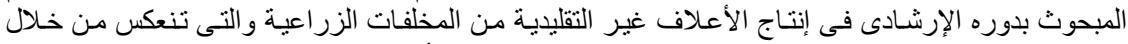

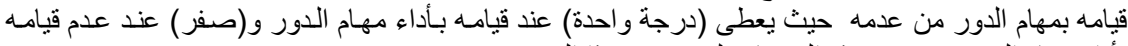

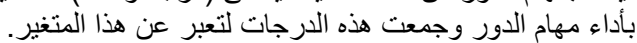

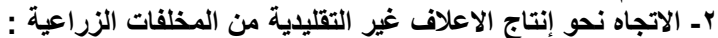

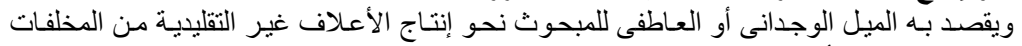

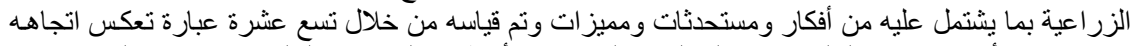

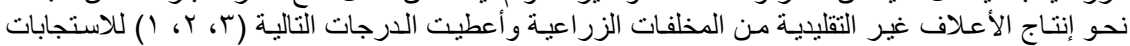

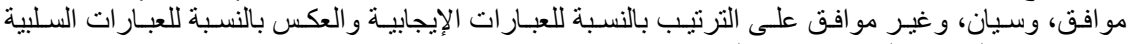
وجمعت هذه الدرجات التعبر عن هذا المتنغير.

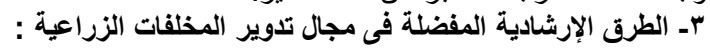

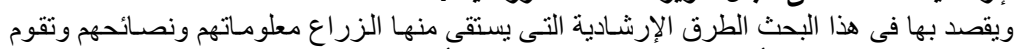

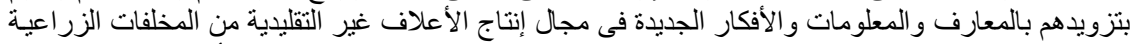

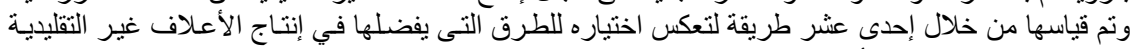

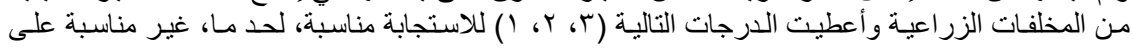
الترتيب.

\section{النتائج ومناقثتها}

أولاً : قيام القادة المحليين بالأدوار الإرشادية فى إنتاج الأعلاف غير التقليدية :

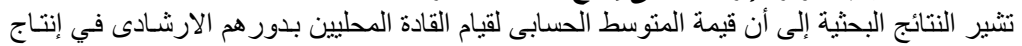

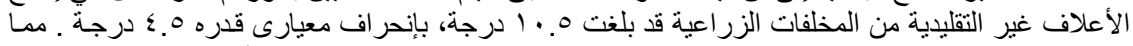

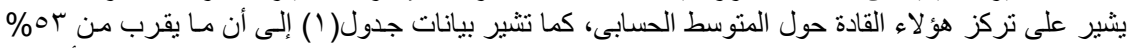

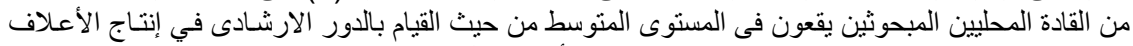

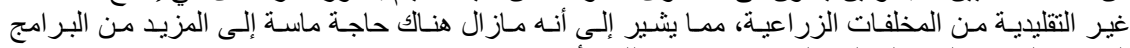
التدريبية لهؤلاء القادة المحليين لزيادة معارفهم بتلك الأدوار .

جدول ( ) : توزيسع القـادة المحليين المبحوثين وفقاً لقيـامهم بـدورهم الإرشـادى فى إنتاج الأعلاف غير

\begin{tabular}{|c|c|c|}
\hline النسبة المئوية \% & العدد & مستوى القيام بالدور الارشادى \\
\hline 19.1 & $T \varepsilon$ & منخفض (V درجة فأقل) \\
\hline or. 9 & $T \leqslant$ & متوسط (^- ؟ ا درجة) \\
\hline TY.Y & $r \mu$ & مرتفع (ع ( درجة فأكثر) \\
\hline $1 \ldots$ & 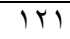 & المجهوع \\
\hline
\end{tabular}

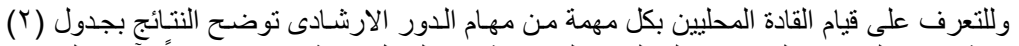

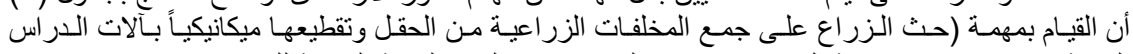

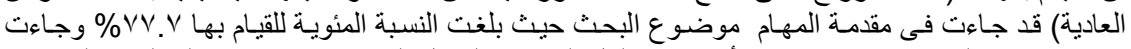

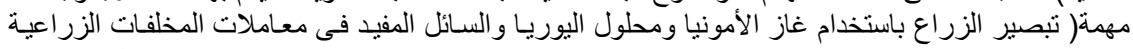

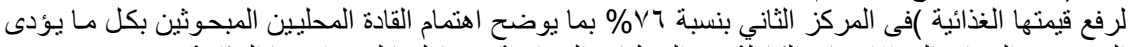

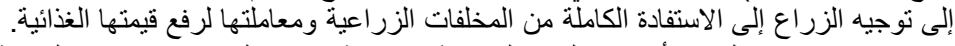

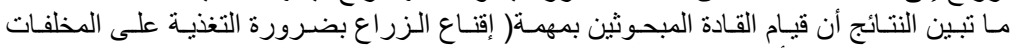

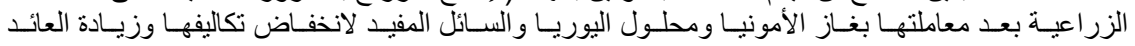


Abou Zaiud, R. H. A.

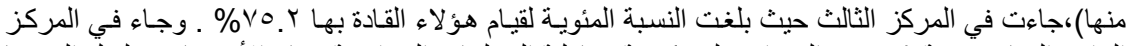

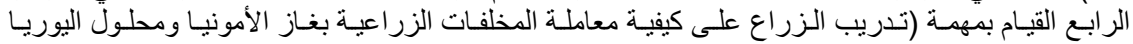

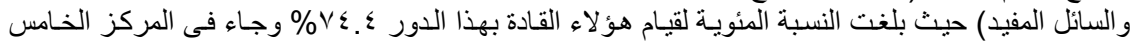

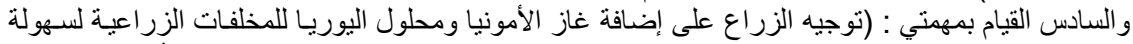

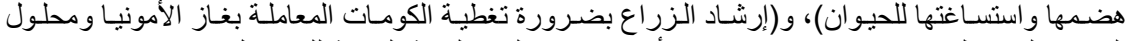

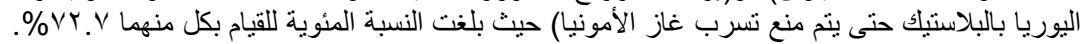

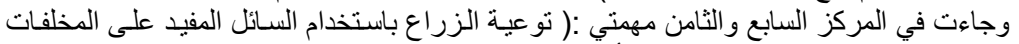

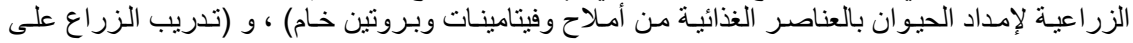

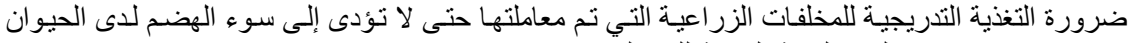

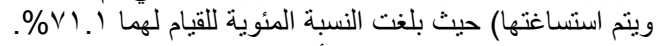

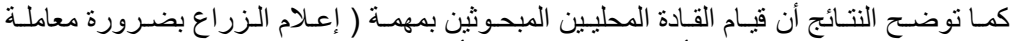

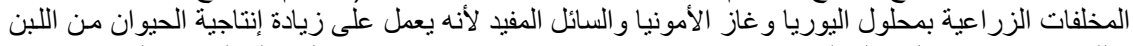

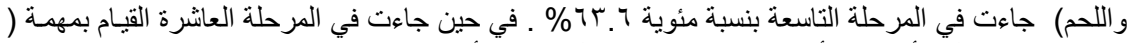

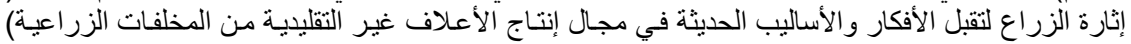

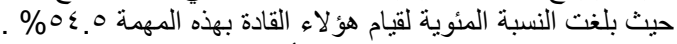

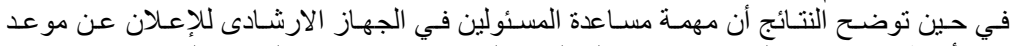

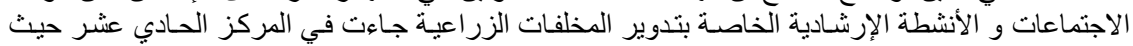

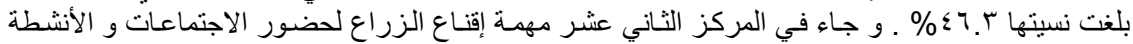

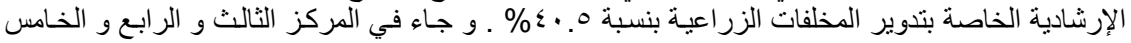

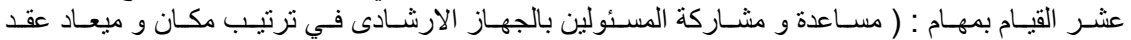

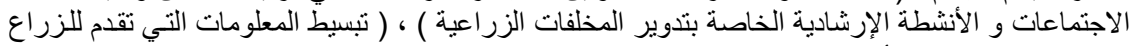

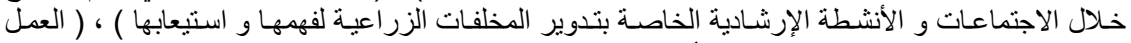

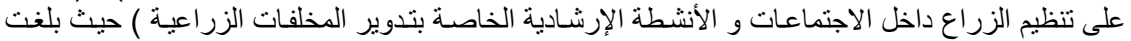

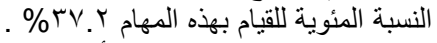

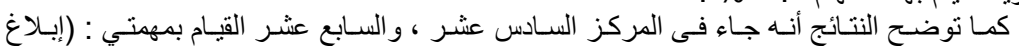

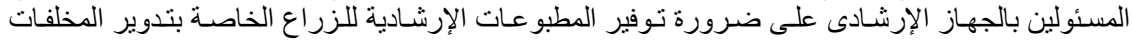

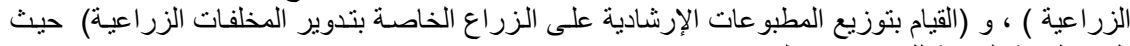

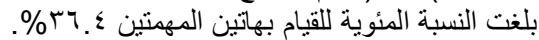

جدول (ץ) : التكـرارات و النسـب المئويـة للمبحـوثين الـذين قـاموا بكل مـن مهام الـدور الارشـادى لإنتـاج الأعلاف غير التقليدية من المخلفات الزراعية.

\begin{tabular}{|c|c|c|c|}
\hline \multicolumn{2}{|c|}{ القبـــام بالدور } & \multirow{2}{*}{ الأدوار } & \multirow[b]{2}{*}{ e } \\
\hline$\%$ & عدد & & \\
\hline$V V . V$ & $9 \varepsilon$ & 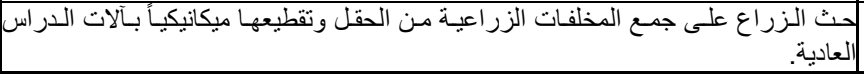 & 1 \\
\hline VT & 94 & 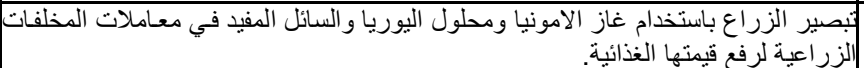 & $r$ \\
\hline Vo.r & 91 & 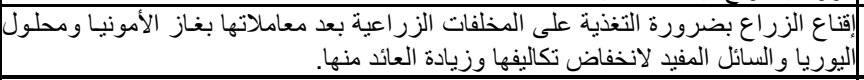 & $r$ \\
\hline$V \varepsilon . \varepsilon$ & 9. & 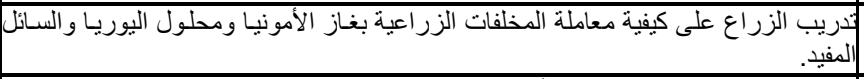 & $\varepsilon$ \\
\hline VY.V & $\Lambda \Lambda$ & |ه استنساغتها للحيو النى إضافة غاز الأمونيا ومحلول اليوريا للهخلفات الزر اعية لسهولة هضمها & 0 \\
\hline$V Y . V$ & $\Lambda 1$ & 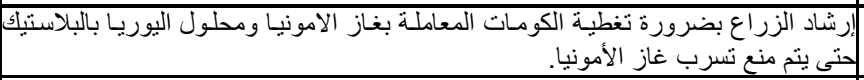 & 7 \\
\hline V1.1 & $\Lambda 7$ & 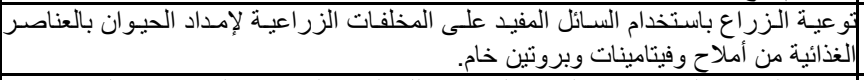 & $V$ \\
\hline v1.1 & 17 & 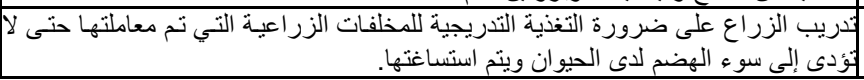 & $\wedge$ \\
\hline
\end{tabular}




\begin{tabular}{|c|c|c|c|}
\hline Tr.7 & V & 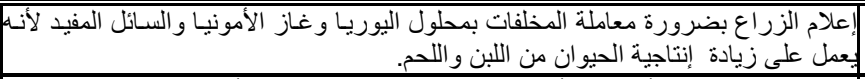 & $\overline{9}$ \\
\hline $0 \leqslant 0$ & 77 & الثخلفات الزراع التقبل الأفكار و الأسـاليب الحديثة في مجال إنتاج الأعلاف غير التقليديـة من & 1. \\
\hline$\leq 7 . r$ & 07 & |لخاصة بتدوير المخلفات الزراعية الإرشادي للإعلان عن موعد الاجتماعات والأنشطة الإرشـادياة| & 11 \\
\hline$\varepsilon \cdot .0$ & $\sum 9$ & إقناع الزراع بحضور الاجتماعات و الأنشطة الإرشادية الخاصة بتدوير المخلفات الزراعية. & TY \\
\hline re.r & ¿० & 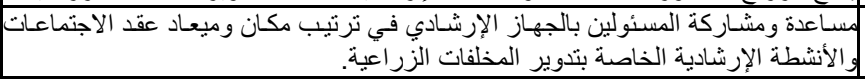 & $\pi$ \\
\hline re.r & $\leq 0$ & 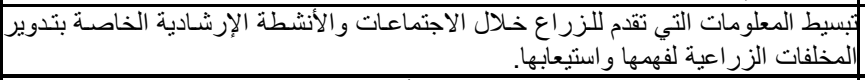 & $1 \varepsilon$ \\
\hline rV.r & $\leq 0$ & |الزر اعية. على تنظيم الزراع داخل الاجتماعات و الأنشطة الإرشادية الخاصـة بتدوير المخلفـات & 10 \\
\hline r. & $\leq \varepsilon$ & |بتدوير المخلفات الزبر اعهية. الإرشاد على ضرورة توفير المطبوعات الإرشادية للزراع الخاصسة & 17 \\
\hline r.. & $\varepsilon \varepsilon$ & |ألقيام بتوزيع المطبو عات الإرشادية على الزراع الخاصة بتدوير المخلفات الزراعية. & IV \\
\hline q.דr & «1 & 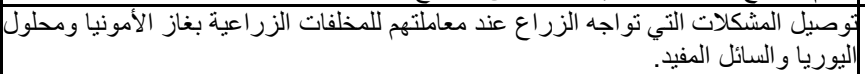 & 11 \\
\hline r. $1 . \varepsilon$ & rA & | & 19 \\
\hline
\end{tabular}

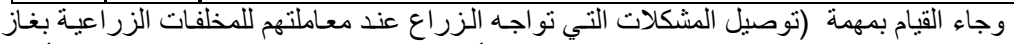

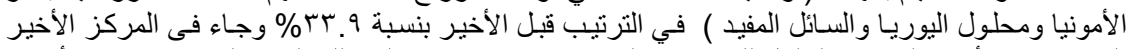

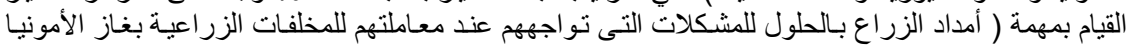

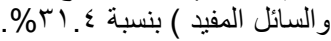

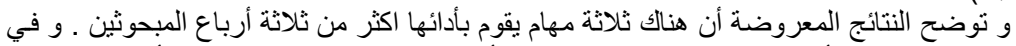

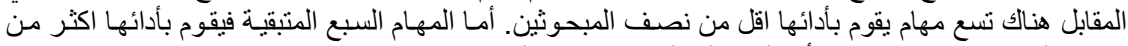

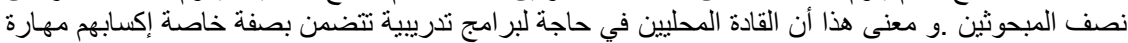
للقيام بالمهام التسع التي تنخفض نسبة القائمين بأدائها.

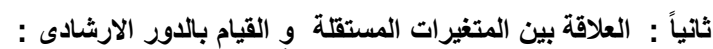

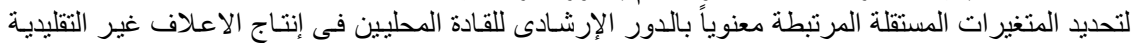

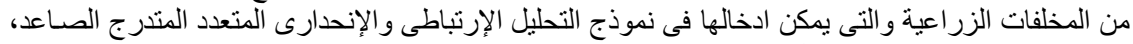

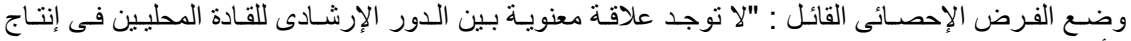

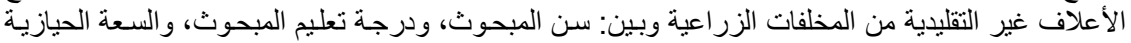

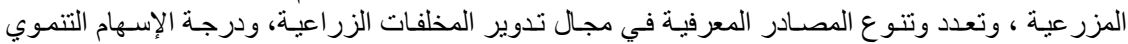

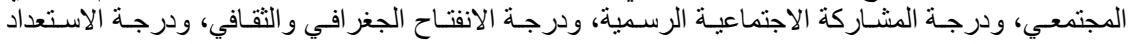

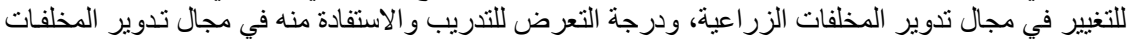

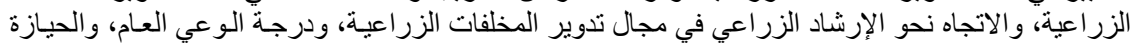

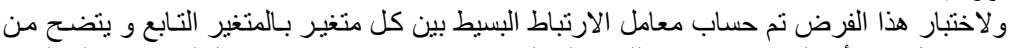
الحيو انية المزر والاتية نواه

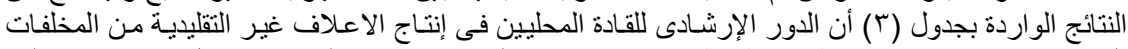

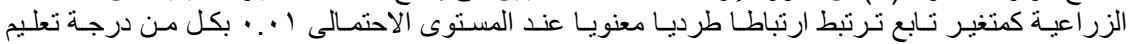

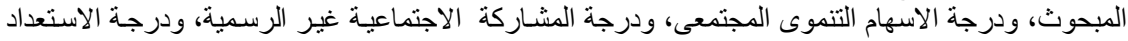

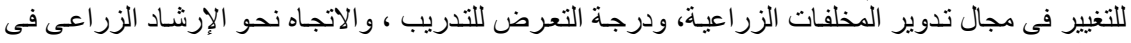

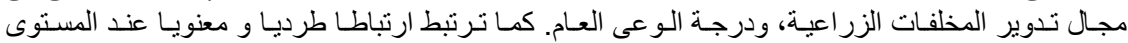

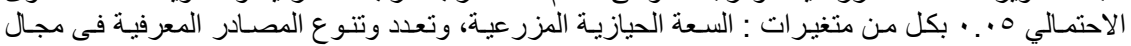

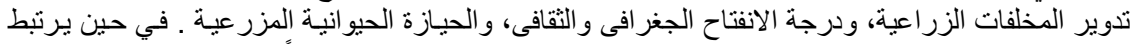

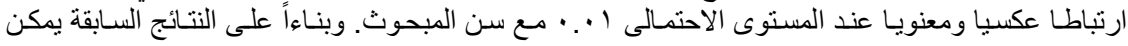


Abou Zaiud, R. H. A.

رفض الفرض الاحصائى فيما يتعلق بجميع المتغيرات المستقلة غيما عاد سن المبحوث و نقبل الفرض البحثي

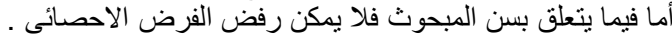

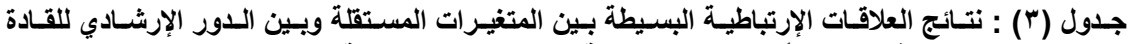
المحليين في إنتاج الأعلاف غير التقليدية من المخلفات الزراعية.

\begin{tabular}{|c|c|c|}
\hline |قيم معاملات الارتباط & المتغيزات المستقلة المدروسة & s \\
\hline$\because Y \leq \Lambda_{-}$ & 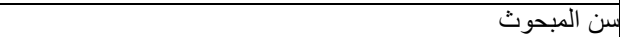 & 1 \\
\hline$\because \leqslant \leqslant T$ & برجة تعليم المبحوث & $r$ \\
\hline$\cdot r \cdot 0$ & السعة الحيازية المزرعية & r \\
\hline$\cdot$ GYV & تعدد وتنوع المصادر المعرفية في مجال تدوير المخلفات الزر اعية & $\varepsilon$ \\
\hline . & لدرجة الإسهام التنموي المجتمعي & 0 \\
\hline$\because Y V Y$ & لدرجة المشاركة الاجتماعية الرسمية & 7 \\
\hline$\cdot r \cdot 0$ & |درجة الانفتاح الجغر افي و الثقافي & $\mathrm{V}$ \\
\hline .101 & درجة الاستعداد للتغيير في مجال تدوير المخلفات الزر اعية & $\wedge$ \\
\hline$\cdot$. & لمرجة التعرض للتدريب & 9 \\
\hline$\because Y 79$ & الاتجاه نحو الإرشاد الزراعي في مجال تدوير المخلفات الزر اعية & $1 \cdot$ \\
\hline$\because Y \wedge T$ & الدرجة الوعي العام & 11 \\
\hline$\cdot$. YY & الحيازة الحيو انية المزرعية & IT \\
\hline
\end{tabular}

ولتحديد العلاقة الارتباطية بين المتغير ات المستقلة مجتمعة وبين الدور الإرشـادى للقادة المحليين

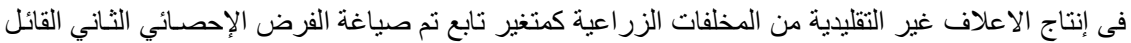

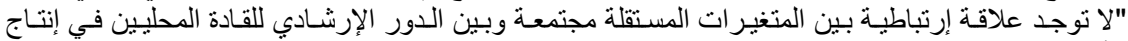

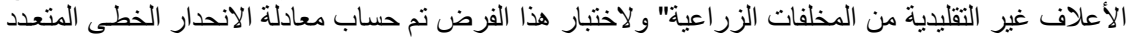

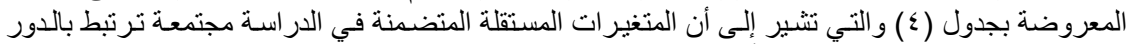

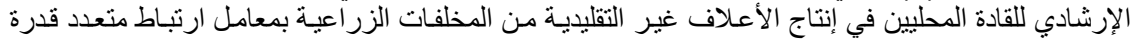

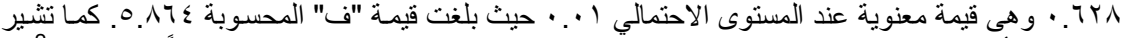

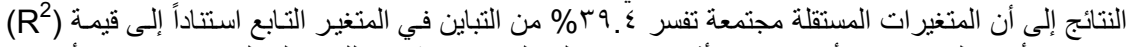

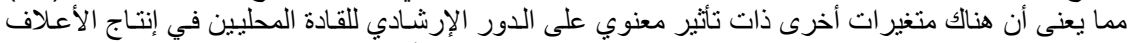

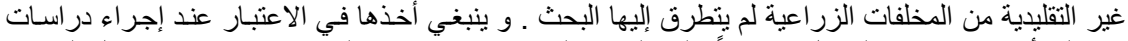

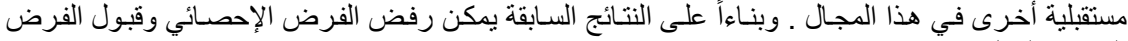
البحثي (البديل).

جدول ( ؛) : نتائج العلاقـات الاتحداريـة (الارتداديـة) بين المتغيرات المستقلة وبين الداتور الإرشـادي للقـادة

\begin{tabular}{|c|c|c|c|}
\hline قيمة "ت & معامل الآحدار & المتغيرات المستقلة المدروسة & 5 \\
\hline 1.YVA- & $\because$. rq_ & سن المبحوث & 1 \\
\hline 1.000 &. $.1 Y \mu$ & | لدرجة تعليم المبحوث & r \\
\hline .79 . & $\because \cdots$ & |السعة الحيازية المزرعية & $r$ \\
\hline $1.79 \mathrm{~V}$ & $\cdot r \leqslant \wedge$ & لتعدد وتتوع المصادر المعرفية في مجال تدوير المخلفات الزر اعية & $\varepsilon$ \\
\hline$\cdot \wedge \leqslant \wedge$ & $\because \cdot V 4$ & الثرجة الإسهام التنموي المجتمعي & 0 \\
\hline$\cdot \wedge \leqslant 9$ & $\because \cdot \wedge 1$ & |درجة المشاركة الاجتماعية الرسمية & 7 \\
\hline. $.1 \mathrm{\mu}$ & $\because \cdots 9$ & الـرجة الانفتاح الجغر افي و الثقافي & $\mathrm{V}$ \\
\hline 1.rY & $\cdot$. YTा & لـرجة الاستعداد للتغيير في مجال تدوير المخلفات الزر اعية & $\wedge$ \\
\hline$r .0 \leqslant V$ & $\cdot r \Lambda T$ & ليرجة التعرض للتنريب & 9 \\
\hline $1.9 \cdot 1$ & $\cdot . M Y$ & الاتجاه نحو الإرشاد الزراعي في مجال تدوير المخلفات الزر اعية & 1. \\
\hline$\cdot$. . 04 &. $.0 \mathrm{~V}$ & |لدرجة الوعي العام & 11 \\
\hline
\end{tabular}




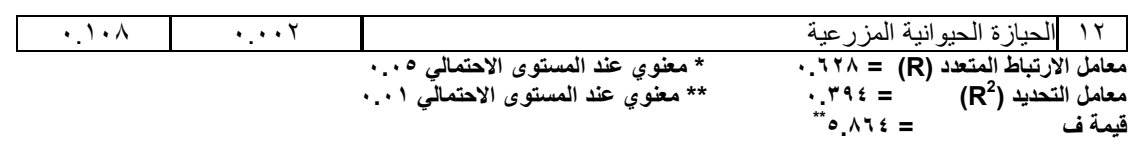

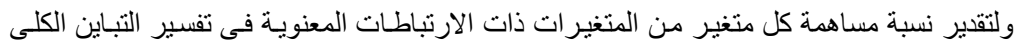

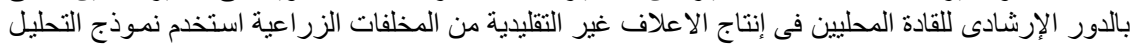

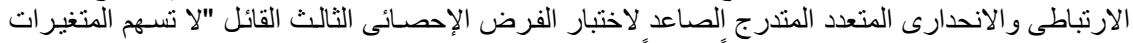

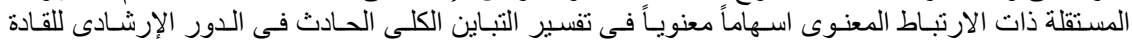

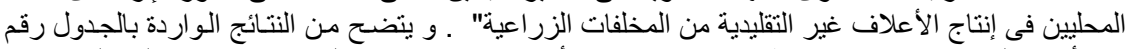

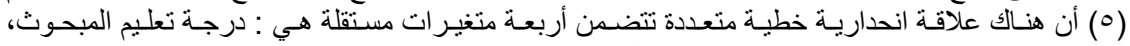

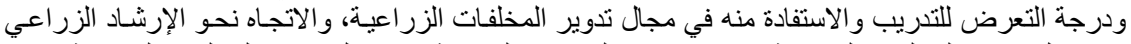

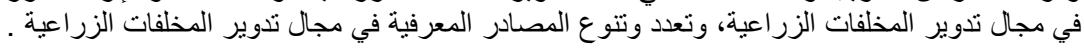
جدول (0) : نمـوذج مختزل بين علاقة المتغيرات المستقلة بالـدور الإرشـادى للقـادة المحليين في إنتاج الاعلاف غير التقليدية من المخلفات الزراعية.

\begin{tabular}{|c|c|c|c|c|c|c|}
\hline |للتباين المفسئة التئية & |التراكمية للتباينة المئنة & قيمة "ت" & الجزئى القياسى الاندار & الانحدار & المتغيرات المستقلة & 5 \\
\hline 19.7 &. .197 & $\varepsilon . r \leqslant \Gamma$ & ..$r T V$ & r. $Y \leqslant$. & برجة تعليم المبحوث & 1 \\
\hline 9.9 &.$r 09$ & r. & $\cdot r \cdot \varepsilon$ & $\cdot . \Omega \mathrm{V}$ & لررجة التعرض للتدريب & $r$ \\
\hline T.r & . RTV & ${ }^{*}$ r. YVq & $\cdot .1 \vee \varepsilon$ & $.1 \leqslant r$ & 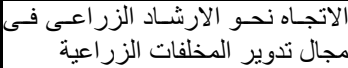 & $r$ \\
\hline r.o & . TOY & * &. .17. &. .197 & 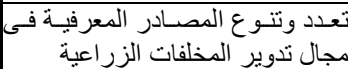 & $\varepsilon$ \\
\hline
\end{tabular}

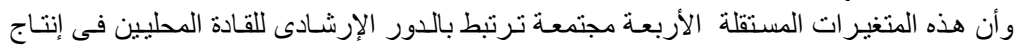

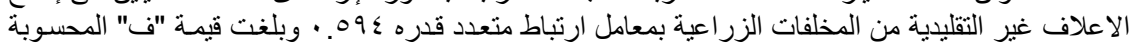

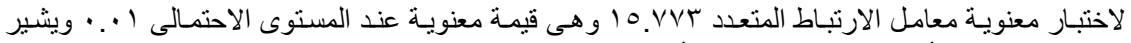

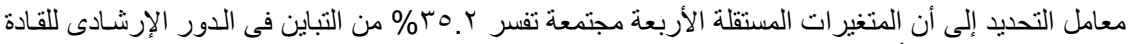

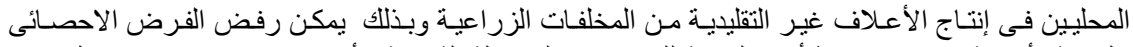

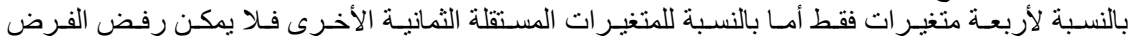

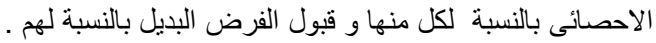

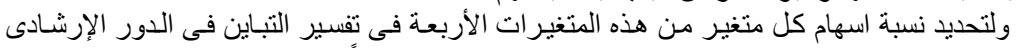

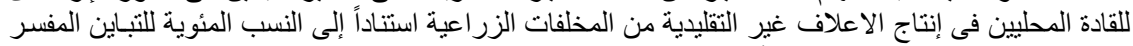

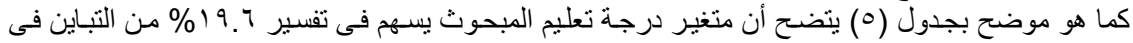

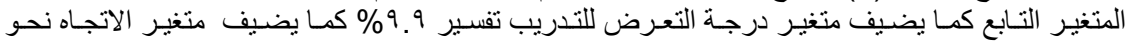

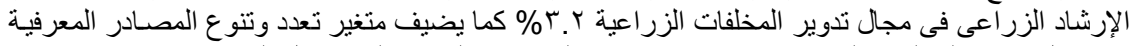

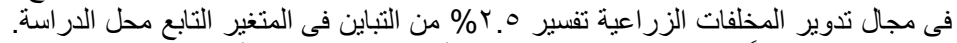

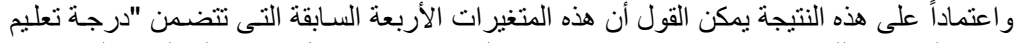

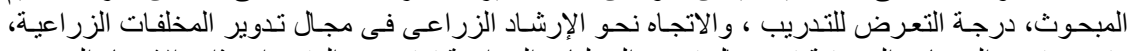

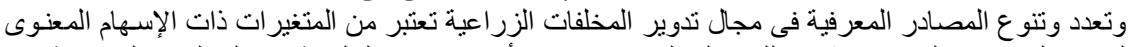

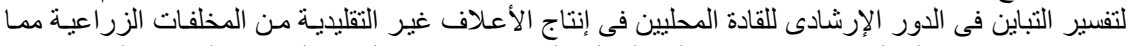

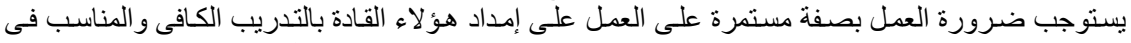

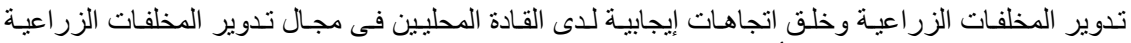

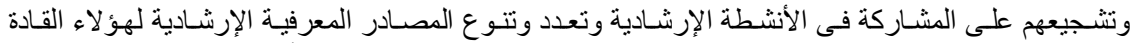

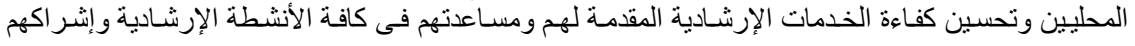


Abou Zaiud, R. H. A.

بكفاءة وفاعلية ومر اعاة الدرجة التعليمية بينهم واستخدام كافة الطرق الإرشادية التى تتناسب مع كافة الدرجات التعليمية ومر اعاة الفروق الفردية بينهم. ثالثاً : الاتجاه نحو إنتاج الأعلاف غير التقليدية من المخلفات الزراعية :

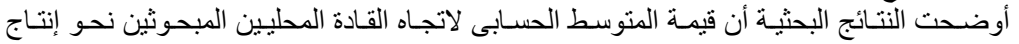

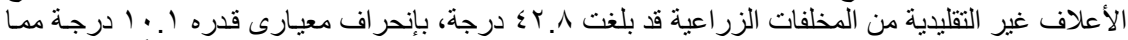

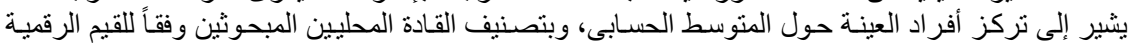

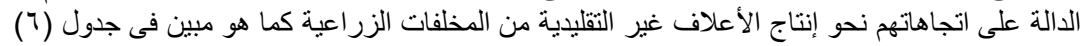

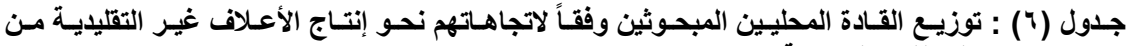
المخلفات الزراعية.

\begin{tabular}{|c|c|c|}
\hline$\%$ & العدد & الفئــات \\
\hline 9.9 & IT & فئة الاتجاه السلبي ( آ درجة فأقل) \\
\hline rT. & $\leqslant 1$ & فئة الاتجاه المحايد (r (r- ؟ ؛ درجة) \\
\hline 07.1 & 71 & فئة الاتجاه الإيجابي (0؛ درجة فأكثر) \\
\hline $1 \cdots$ & $|Y|$ & المجمـوع \\
\hline
\end{tabular}

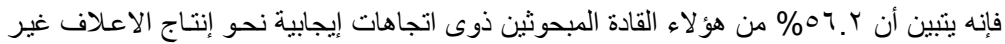

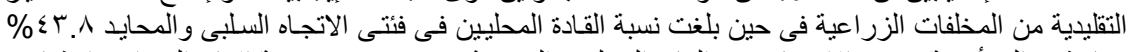

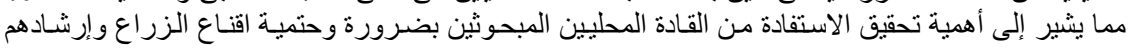

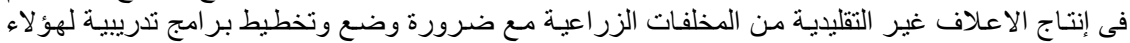

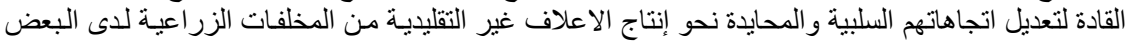

رابعـاً : الطرق الإرشـادية التـى يفضلها القـادة المحليين المبحـثين فـى إنتـاج الأعلاف غير التقليليـة مـن

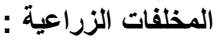

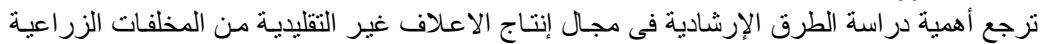

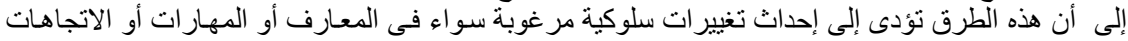

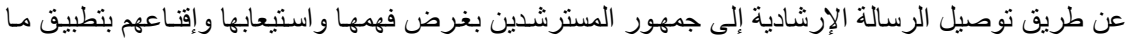

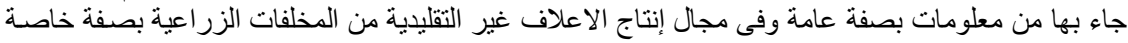

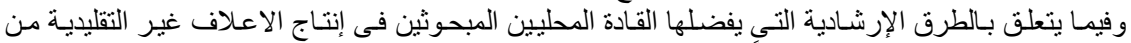

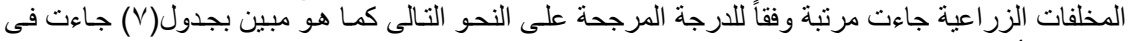

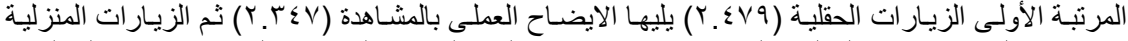

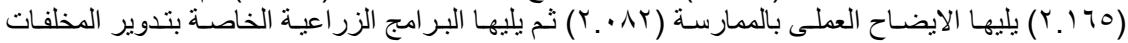

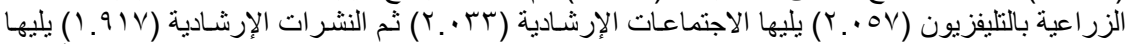

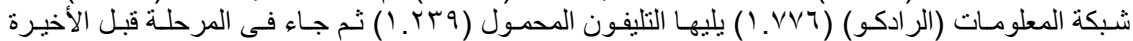

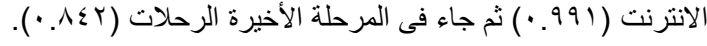

جدول (V) : الطرق الإرشادية التي يفضلها القادة المحليين المبحوثين في إنتاج الأعلاف غير التقليدية من المخلفات الزراعية.

\begin{tabular}{|c|c|c|c|}
\hline الترتيب & الارجة المتوسطة & الطرق الإرشاديـة & s \\
\hline 1 & Y. $\leqslant \vee q$ & |الززيارات الحقلية & 1 \\
\hline r & $r . r \leqslant V$ & | ل الإيضاح العملى بالمشاهدة & $r^{2}$ \\
\hline 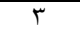 & 5.170 & | ل الزيار ات المنزليـة & $r$ \\
\hline$\varepsilon$ & t.Ar & | الإيضاح العملى بالممارسة & $\varepsilon$ \\
\hline 0 & Y.OV & ألبر امج الزر اعبة الخاصة بتدوير المخلفات الزر اعبة بالتليفزيون & 0 \\
\hline 7 & t. & | الاجتماعات الإرشادية & 7 \\
\hline
\end{tabular}




\begin{tabular}{|c|c|c|c|}
\hline V & $1.91 \mathrm{~V}$ & النشـرات الإرشادية & $\mathrm{V}$ \\
\hline$\Lambda$ & $1 . V \times 7$ & شُبكة المعلومات (الر ادكو) & $\Lambda$ \\
\hline 9 & $1 . r+9$ & |التليفون المحمول & 9 \\
\hline 1. & .991 & | الانترنت & 1. \\
\hline 11 & $\cdot \wedge \leq Y$ & |الرحلات الإرشادية & 11 \\
\hline
\end{tabular}

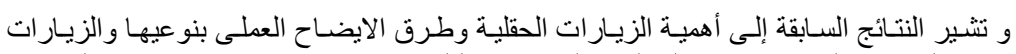

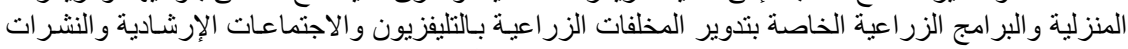

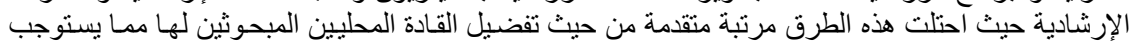

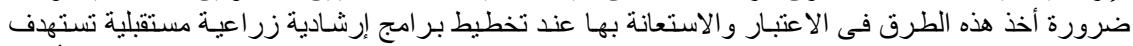

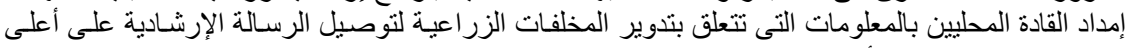

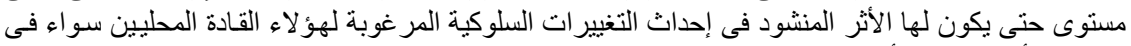

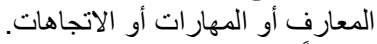

خامسـاً : المشكلات التـي تواجـه القـادة المحليـين المبحـوثين عندات القيـام بـأدوارهم في إنتـاج الأعلاف غير

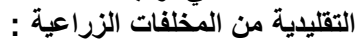

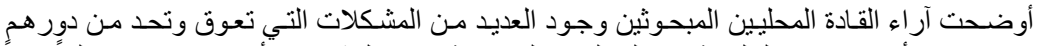

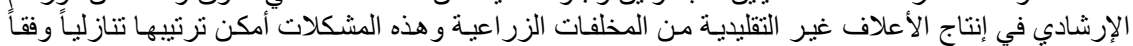

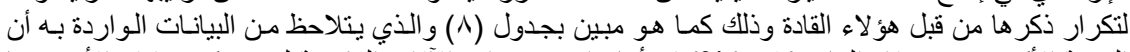

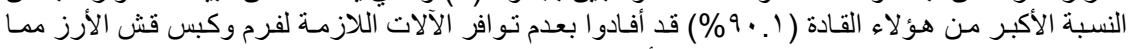

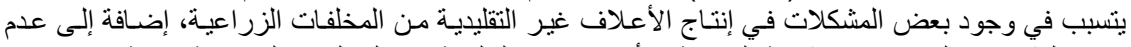

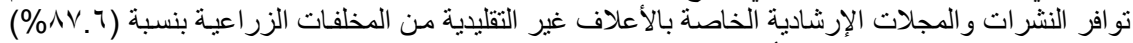

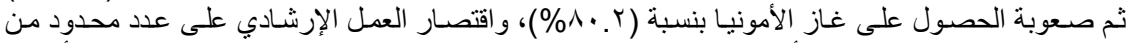

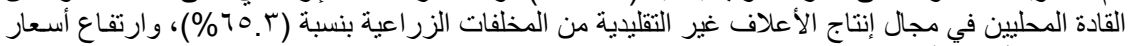

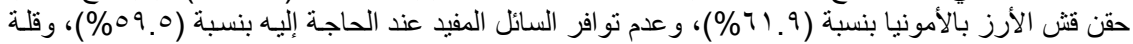

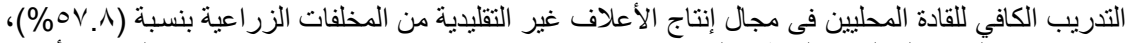

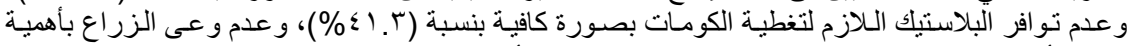

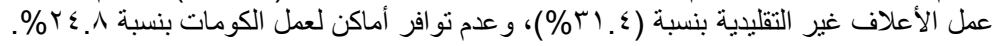

جدول (^) : المشكلات التى تواجه القادة المحليين المبحوثين عند القيام بأدوارهم فى إنتاج الاعلاف غير

\begin{tabular}{|c|c|c|c|}
\hline$\%$ & 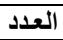 & المشكــلات & ? \\
\hline $9 . .1$ & 1.9 & |عدم توافر الآلات اللازمة لفرم وكبس قش الارز & 1 \\
\hline NV. 7 & 1.7 & |عدم تو افر النشرات والمجلات الإرشادية الخاصة بالأعلاف غير التقليدية & r \\
\hline$\lambda \cdot . r$ & $9 \mathrm{~V}$ & لصعوبة الحصول على غاز الأمونيا & $r$ \\
\hline 70.5 & v9 & |غير التقليدية من الإرخلفات على الزراعية عددود من القادة المحليين فى مجال انتاج الاعلاف & $\varepsilon$ \\
\hline 71.9 & Vo & |رتفاع أسعار حقن قش الأرز بالأمونيا & 0 \\
\hline 09.0 & VT & |عدم تو افر السائل المفيد عند الحاجة إليه & 7 \\
\hline OV.A & $v \cdot$ & الزئة اعبةريب الكافى للقادة المحليين فى مجال إنتاج الأعلاف غير التقليدية من المخلفات & $\mathrm{v}$ \\
\hline «1. & 0. & | لعدم تو افر البلاستيك اللازم لتغطية الكومات بصورة كافية & $\Lambda$ \\
\hline r1. & $r \wedge$ & لعدم وعى الزراع بأهمبة عمل الأعلاف غير التقليدية & 9 \\
\hline$r \leqslant . \wedge$ & $r \cdot$ & |عدم تو افر أماكن لعمل الكومات العلفية & 1. \\
\hline
\end{tabular}

مما سبق يتضح وجود مجمو عة من المشكلات التي تحد من قيام القادة المحليين بـأدوار هم في إنتاج

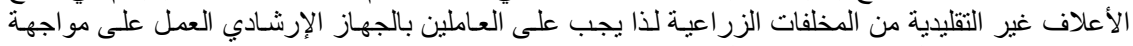

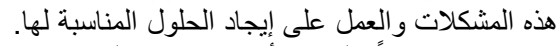

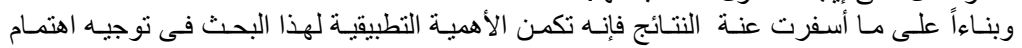

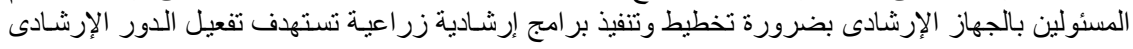


Abou Zaiud, R. H. A.

للقادة المحليين فى إنتاج الأعلاف غير التقليدية من المخلفات الزر اعية عن طريق توفير التدريب الكافى لهم فى إلى

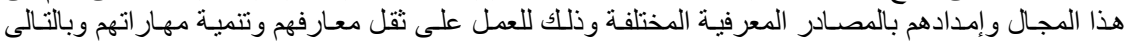

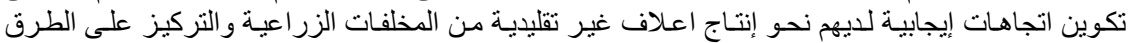

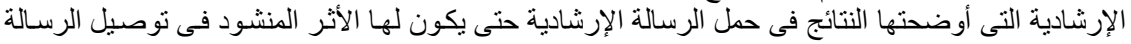

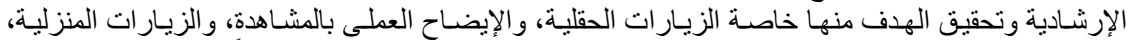

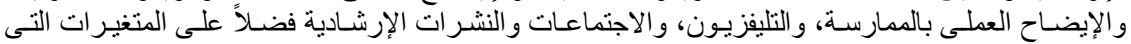

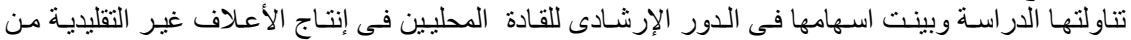

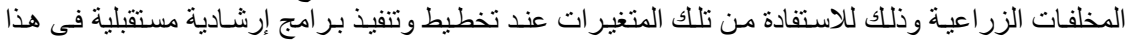

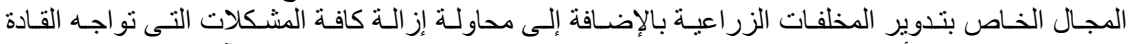

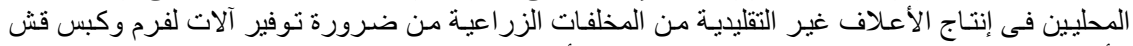

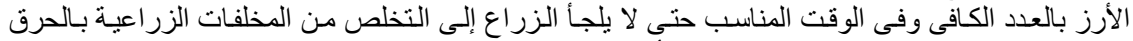

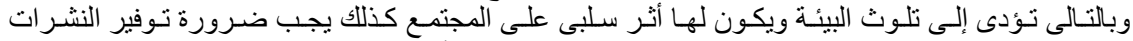

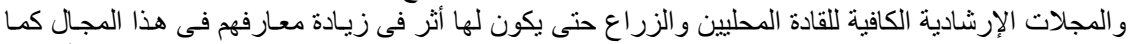

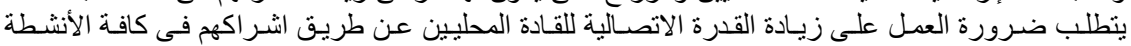

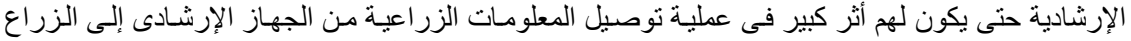

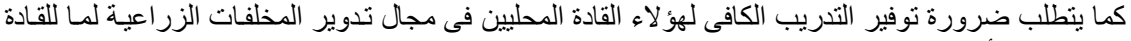

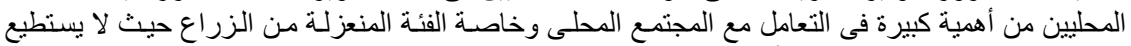

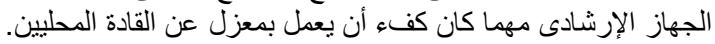

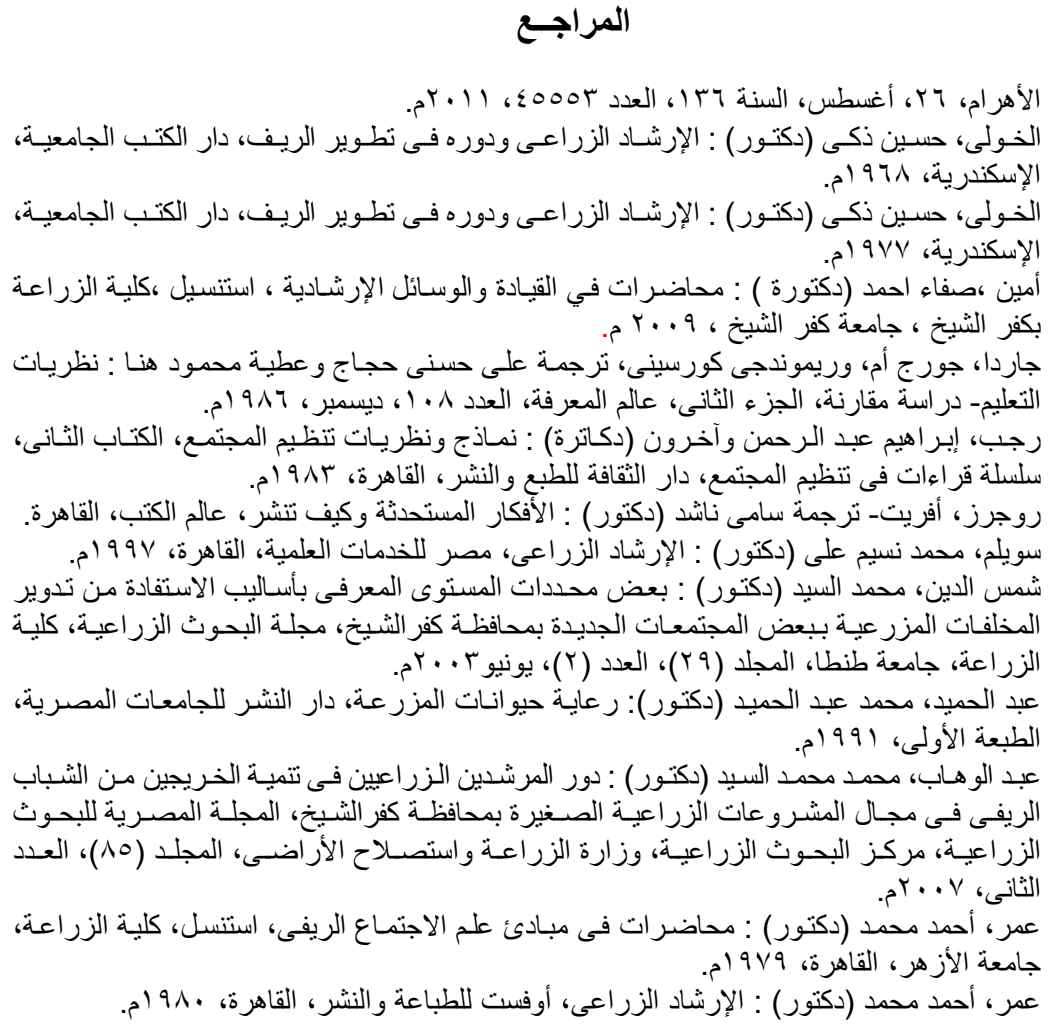




$$
\begin{aligned}
& \text { مركز المعلومات ودعم اتخاذ القرار، محافظة كفر الثيخ، ـ أبم. }
\end{aligned}
$$

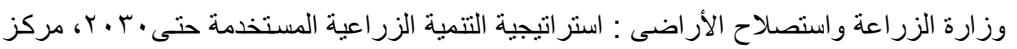

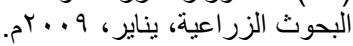

(1) Wolman B. Ed. Dictionary of Behavioral Science Macmillan Press LTD, New York. 1975.

(2) http://digital.ahram.org.eg/articles.aspx?serial=40774\&eid=907.

(3) http://news.Maktoob.com/article/585262/

(4) http://www.elbashayer.com/news-128987.html.

(5) http://www.Lightsislam.com/t2606-topic.

\title{
THE EXTENSION ROLE OF LOCAL LEADERS IN THE PRODCUTION OF NON-TRATITIONAL FEED FROM AGRICULTURAL WASTE IN KAFR EL-SHEIKH AND BIALA DISTRICTS, KAFR EL-SHEIKH GOVERNORATE
} Abou Zaiud, R. H. A.

Agric. Extension\& Rural Develop. Res. Inst. - ARC

\begin{abstract}
The main objective of this study is identifying extension role of local leaders in the production of non-traditional feed from agricultural waste at Kafr el-Sheikh and Biala districts in Kafr El-Sheikh governorate, A sample of 121 local leaders was selected:83 from Kafr El-Sheikh districts and 38 from Biala districts. Data were collected through personal interviews. Frequencies, percentages, means, standard deviation the correlation coefficient and regression, , multiple regression and stepwise were used to analyze the data.

The most important results were:

1. Nearly $53 \%$ of respondents from perform extension role at a medium level.

2. The extension role of local leaders in the production of non-traditional feed from agricultural waste as the dependent variable was divaricately correlated with the twelve independent variables at the level of 0.05 at least,

3. The independent variables combined were multivariate correlated with extension role with a coefficient of 0.628 which is significant at 0.01 levels.

4. The twelve independent variables explained about $39.4 \%$ of the total variance in the dependent variable with degree of exposure to training and the attitude towards extension making significant unique contribution.

5. Four independent variables explain about $35.2 \%$ of the total variance in the dependent variable: These are Education, the degree of exposure to training, the attitude towards agricultural extension, and the multiplicity and diversity of sources of knowledge.

6. The majority of leaders $(56.2 \%)$. have positive attitudes toward non-traditional feed production from agricultural waste.
\end{abstract}


Abou Zaiud, R. H. A.

7. The best extension methods favored by respondents were farm and home visits, demonstration, agric. TV programs t, meetings and news extension bulletins.

8. There are many problems facing the leaders of respondents when they their roles in the production of non-traditional feed from agricultural wastes: the lack of machinery chopping and baling hay rice and releases, and the difficulty of obtaining ammonia gas, and limited extension work on a limited number of local leaders, and rising prices of rice straw ammonia injection, and the lack of liquid useful when you need it, and lack of adequate training for local leaders in the production of nonconventional feed from agricultural waste.

\footnotetext{
كلية الزراعة - جامعة المنصورة

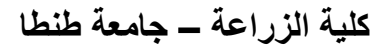

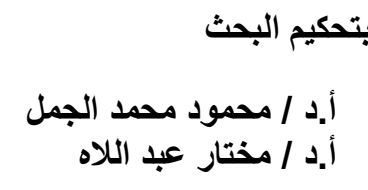
أ.د / مختار عبد الثلاه محد الجمل 